Technological University Dublin ARROW@TU Dublin

\title{
Connected Health: An Open Innovation Perspective.
}

Anushree Priyadarshini

Technological University Dublin, anushree.priyadarshini@tudublin.ie

Maria Quinlan

University College Dublin

Gerardine Doyle

University College Dublin

Follow this and additional works at: https://arrow.tudublin.ie/buschacart

Part of the Business Administration, Management, and Operations Commons

\section{Recommended Citation}

Priyadarshini, A., Quinlan, M., \& Doyle, G. (2017). Connected Health: An Open Innovation Perspective. Applied Clinical Research, Clinical Trials and Regulatory Affairs, 4(1), 55-59. doi:10.2174/

2213476 X4666170106154613

This Article is brought to you for free and open access by the School of Accounting and Finance at ARROW@TU Dublin. It has been accepted for inclusion in Articles by an authorized administrator of ARROW@TU Dublin. For more information, please contact arrow.admin@tudublin.ie, aisling.coyne@tudublin.ie, gerard.connolly@tudublin.ie.

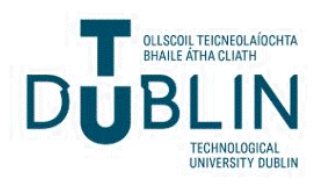


Connected Health: An Open Innovation Perspective

Anushree Priyadarshini*a, Maria Quinlan ${ }^{\mathrm{a}}$, and Gerardine Doyle ${ }^{\mathrm{a}}$

${ }^{a}$ Applied Research for Connected Health (ARCH) and UCD College of Business, University College Dublin, Belfield, Dublin 4, Ireland

\begin{abstract}
The concept of connected health has gained traction in recent years as a new technology enabled and networked model of healthcare delivery. It is often used as an umbrella term for eHealth, digital health, health informatics, telemedicine, mHealth and involves the establishment and management of a network of stakeholders with the aim of improving healthcare quality and outcomes. Yet a lack of open interactions and knowledge networks and the missing integration of the larger constituency of interdisciplinary experts are limiting the execution of the model and restricting its potential to devise services and interventions around patient's needs with shared health related data. Drawing parallels between the concept of connected health and open innovation, the networked innovation model, which involves efficient management of knowledge flows and complex networks for successful innovations; in this paper we outline the practice of open innovation in healthcare and suggest connecting stakeholders in the healthcare ecosystem in an open innovative format. In doing so we present a categorization of firms in the healthcare ecosystem into open innovation profiles for becoming connected and propose an open innovative framework for maximizing the potential of the concept of connected health.
\end{abstract}

Keywords: Connected health; Open innovation; Healthcare ecosystem; Innovation network

\section{INTRODUCTION}

The phenomenon of increasingly networked process of innovation in which companies profit from external knowledge is called 'open innovation', a paradigm that assumes that organizations can and should combine internal ideas, external ideas and paths to market, as they look to advance their technologies [1]. Advantages of this strategy are that firms can make use of pooled human resources, technology and customer information. These can result in speeding up the innovation process, spreading the risk of innovation failure, reducing the costs of technological development or market entry and improving the achievement of economies of scale in production. This apparently new paradigm, involves efficient management of knowledge flows and complex networks for successful innovations [2, 3].

The concept overlaps well with the diverse features of 'connected health'. Indeed, the range of complex stakeholders, technologies, objectives and disciplines involved in connected health tend to exponentially increase its heterogeneity and calls for the establishment and management of networks, similar to that which is required in an open innovation scenario. Pagilari [4] and Dooris [5] suggest that the potential of connected health may be maximized by the involvement of a wider community of disciplinary experts, including managers and accountants, social scientists and legal experts. While it can be argued that even though not currently strategically rolled out in practice, the open innovation approach forms the premise for the concept of connected health to fully flourish [6]. Examples like GSK and the Hammersmith Hospital's collaboration for a Clinical Imaging Centre; NHS Trusts in Scotland and Wyeth Pharmaceuticals' Experimental Medicine project are fast growing [7]. Yet as outlined by Eaton [8] it is noteworthy that the lack of open interactions and knowledge networks and the missing integration of the larger constituency of interdisciplinary experts are increasingly the underlining factor for a missing open innovative framework in the healthcare system. Similarly, Brodie [6] also suggests that the size, level of complexity of the organization, difference in attitudes of the partners and lack of any rewards limit the collaborative opportunities in the healthcare arena. Therefore as an approach for players in the healthcare landscape to be connected, in this paper firstly we propose a categorization for firms who operate within the healthcare ecosystem into open innovation profiles for becoming connected. Secondly we propose an open innovative framework for the implementation of connected health. *Address correspondence to this author at the Applied Research for
Connected Health and UCD College of Business, University College
$\begin{aligned} & \text { Dublin, Ireland; Tel: +353-1-716-5411, } \\ & \text { anushree.priyadarshini@ucd.ie. }\end{aligned}$
gerardine.doyle@ucd.ie

\section{OPEN INNOVATION IN HEALTHCARE}

Healthcare research is under increasing pressure to innovate in order to counter rising operational costs and depleting pipelines [9]. While currently the focus of innovation in healthcare is on patient care and disease mitigation [10]; demographic changes, advancements in medical science, major scarcities of human and financial resources and the increasing empowerment of users is fast resulting in a paradigm shift towards prevention, participation and coaching [11]. This is essentially a move from merely looking at healthcare via the biomedical lens of diagnosis and treatment, towards a more holistic social model of healthcare which incorporates a person's wider social and cultural factors. Boote et al. [12] argue that for the advancement of research and development in health care, it 
is crucial to integrate the users in health and social research. Supporting this stance Dahlander and Gann [13] also suggest that although traditionally integration of users in health care research was marred by significant costs, advancing technologies and usage behaviors today suggest that the integration of users into innovation activities has become quite feasible and cost-effective.

Open innovation is increasingly touted as the business model for growing value and innovation through partnership. The concept, in which organizations collaborate on research with users and other external partners, is progressively showing strong potential to contribute to improvements in the quality of healthcare innovation and delivery [7]. While it is gaining traction in the form of typologies like clinicians forming a network for healthcare innovation (example: The Society of Physician Entrepreneurs) and as public health systems encouraging digital health companies to engage with them (example: eHealth Connect, Ireland), the key application of open innovation in healthcare currently has been experimental medicine via patients as innovators [14]. In this approach, academic researchers, clinicians and industry collaborate with patients for developing healthcare innovations. Another avenue has been identification and collaboration with persons who suffer from a health problem and independently develop solutions for it [14]. For instance, in 2004 a British process engineer, Tal Golesworthy, diagnosed with Marfan syndrome, designed his own heart textile implant when he realized it was better than an aortic valve replacement. His 'lay' solution has been implanted in 23 other people since then [15]. Another example is that a mother of a young woman with vaginal adenocarcinoma who explored and suggested that the cause of the disease might have been diethylstilboestrol; the mother of another patient was the first to hypothesize that a low maternal serum (alpha) fetoprotein concentration might be a marker for trisomy [16]. These examples reinforce the significance of integrating users in health care research.

Thus far, integrating the users/care givers in healthcare research has largely been limited to the incorporation of patients in the reviewing and testing stage of the research and development process [12]. However, there is an increasing need to move beyond blockbuster drugs and to renew the focus on medicines and diagnostics so that smaller groups of patients with specific unmet needs can be targeted. Merging technology with biology is required so that the collection, analysis and sharing of data can result in developing clinical insight relating to patient care and response to treatments. Having a range of funding sources, including from research councils to commercial entities is needed and patients must be empowered so that they strive for greater participation in decisions relating to the choice of their treatment and care. Therefore, further to the just user collaboration, a more integrated approach in the healthcare sector is called for, a connected health approach, that aligns healthcare providers with industry, with caregivers, patients and payers to integrate multiple healthcare solutions [7]. Given the current technological developments, especially the convenience of interactive web-based technologies that enable active participation of a wider group of stakeholders, this can be achieved by a culture change in healthcare and close collaboration between healthcare, industry and regulatory stakeholders in an open innovative model [17].

\section{OPEN INNOVATION PROFILES FOR CONNECTED HEALTH}

To connect stakeholders in the healthcare ecosystem for an open innovative format, it is essential to first categories companies based on their business needs and the different innovation strategies [18]. The classification can assist mapping firms based on their business efficiencies and value so that it can be identified to whom firms must open, within and across categories for successful connections.

To adapt to the unprecedented change in the healthcare industry, firms are adopting different innovation strategies to offer healthcare solutions [19], and based on these the companies can be categorized as follows:

Products based: firms that develop product or services and progress along the drug development process. These firms generate value by either licensing their products to pharmaceutical companies or by commercializing them.

Platforms based: firms that are engaged in improving processes and developing new capabilities, internally or through collaborations.

Technology based: firms that develop new technologies for all aspects of healthcare.

Hybrid: firms that are engaged in innovating revenue generation, moving from sales of drugs, diagnostics or devices. These focus on combining technology and platforms with services and the creation of products.

Growing complexities, advanced technologies and easy access to highly qualified experts that are outside the confines of the companies, alongside with mounting pressure on time and cost is rapidly advancing the development of open innovation in the healthcare industry. For example, pioneering the concept, Eli Lilly as early as in 2002, established networks of the global pharmaceutical companies [20], namely the Fully Integrated Pharma Network, the Phenotypic Drug Discovery Initiative, the Target Drug Discovery Initiative and Chorus for collaborative research [21]. In 2007, GlaxoSmithKline (GSK) launched its Centre for Excellence for External Drug Discovery, for complete focus on drug discovery alliances with external partners [22]. Similarly reducing its R\&D budget Pfizer in 2010, established Centers for Therapeutic Innovation, with an aim to develop global partnerships between Pfizer and academic medical centers [23]. While elements of a more open business model for pharmaceutical R\&D are increasingly becoming evident [24], the approach has not been adopted to harness open interactions beyond $\mathrm{R} \& \mathrm{D}$ projects where healthcare companies are accessing external knowledge either to manage limited development times and costs, or for getting external information and know-how that companies do not have. Open innovative interactions amongst all players in the healthcare ecosystem and development of knowledge networks based upon profiling of firms as outlined above can result in the integration of the larger constituency of interdisciplinary experts and can be the underlining factor in implementing connected health with an open approach.

\section{OPEN INNOVATION FRAMEWORK FOR CONNECTED HEALTH}


While drawing open innovation profiles for firms in the healthcare sector forms the starting point of an open approach to connected health, connecting these firms with other stakeholders in the ecosystem calls for an understanding of the requirements of the concept to build solutions. In this vein it can be envisaged that the demand side of developing connected health solutions on the ground involves several factors. These include creating a patient's health record; building a lifelong health history for a patient from information held in multiple, diverse systems; joining the different systems on different platforms; interconnecting diverse systems so that they can interoperate; developing communication between remote systems and achieving performance and scalability [25]. Thus working from the requirements towards solutions, taking into consideration the current as well as the required perspectives of the stakeholders, an open connected health model that involves engaging with different parties, is suggested (Fig. 1).

Fig. 1. An open interactive connected health model.

The framework outlines that for the healthcare system to be integrated and interactive at multiple levels and for open interactive connected health to become a reality, continuous interoperable health data must flow between patients and their care providers bi-directionally in real time. This can be achieved by creating an access portal that acquires and integrates the data in collaboration with the different players in the ecosystem. The key elements required here include ensuring access, collection and sharing of information across parties; for pharmaceutical firms to work in collaboration with patients, care providers and amongst themselves to create platforms to achieve digitalization and connectedness of the health system. Patients need to become more involved in order to better track and manage their health by using tools that are outside of traditional medical settings, leveraging the formal healthcare system information to advance their engagement with their circle of care; and services between care providers (hospitals, clinics and third parties such as home-care providers and informal care providers) to be coordinated through connectivity, allowing for seamless collaboration.

Implementation of this open collaborative approach in healthcare, like in other industries requires focusing on the operational and ownership complexities [24]. These call for firstly exploring the existing openness amongst the different players in the ecosystem as against the connected framework. This is to be followed by conducting a gap analysis and then designing the execution plan which could take different routes. For example routes like strategically driven, top-down centralized approach common in fast moving consumer goods (FMCG) organizations where the market is demanding with high competition and achieving revolutionary innovations is difficult [26]; or strategically driven, distributed approach as is followed by energy companies that in small groups make contacts with potential partners for collaboration [27]. Other routes could be bottom up evolutionary approaches, either centralized or distributed, that are driven by environmental conditions like market forces as in the case of the telecommunications industry [28].

Similarly managing the ownership complexities of implementing an open collaborative approach in healthcare requires exploring the influence of the network participants on getting connected and their flexibility around the outcome of participation. Attitudes may vary amongst partners about intellectual property (IP) rights [6]. Also misconceptions that open innovation underrates and weakens IP protection may limit the collaborative approach. Based on the scenario of these complexities, agendas and directions can be designed. Like defining at the onset of the collaboration the ownership and legal rights if an IP is jointly created. How value will be derived by using IP for increasing returns and if goals and milestones of the collaboration are not met, identifying what would be the potential exit strategies [29].

\section{LIMITATIONS AND RECOMMENDATIONS}

Apart from operational and ownership complexities, limitations to achieving a fully connected health care system include need for changing workflows and processes. As these tend to be engrained in organizational working, adopting an open connected health model that involves aligning with other organization's cultures and strategies can be quite a limiting factor [29]. The sheer size and complexity of certain partners including their bureaucratic imperatives may also limit collaborative opportunity [6].While personal career priorities and cultural resistance from the healthcare professionals may inhibit them from embracing the approach. Concerns around lack of evidence on the cost effectiveness of the model, lack of a legal and regulatory framework, inequality in access to technology to patients and care givers and need for common interoperability standards may be other factors that are obstacles in the achievement of a fully connected health care system [30]. 
Overcoming these limitations for improving networking and collaboration, it is critical to first identify outputs that are mutually beneficial to all parties. Ensuring trust and willingness to share expertise, data, rewards as well as risks can add to the relationship and what could be achieved through the collaboration [6]. Additionally, an open collaborative approach in healthcare requires developing clear structures for data protection; security and privacy arrangements in place for sharing data from healthcare apps with electronic health records. Patients' involvement can be elicited by giving them control of their data with mechanisms in place to allow them to see who is using their data and for what purposes. Similarly co-designing of solutions with healthcare professionals, patients and care givers can be harnessed by gathering evidences on the economic benefit of their involvement [30]. State can support crowd sourcing and crowd funding initiatives and can address regulatory challenges by developing incentives like open innovation credits, common IP frameworks and public private partnerships that can facilitate the development of an open collaborative healthcare ecosystem [31].

An open model for practicing connected health is not just about collaboration amongst multiple stakeholders across disciplines and across levels but also about associations beyond regions and nations [32]. It therefore requires developing an open culture in organizations where working with different players in the ecosystem is accepted and endorsed. Procedures like cross functional networks beyond borders are followed and skillsets are advanced for open collaborative working [33]. By developing global policies and creating open innovation-friendly markets and regulatory conditions for cross border health services, the concept may well be developed as a new open, inclusive, multi-stakeholder, user-centric approach that can address the contextual challenges of connected health services.

\section{CONCLUSION}

There is a need for the healthcare system to adapt to more effective ways of developing networks and collaboration that span beyond just R\&D projects [11]. Open innovation, as discussed above is a concept of vital interest in such a scenario. It holds important synergies with the connected health approach and thus can significantly impact the adoption of the approach for sustainable networks and advanced outcomes in the healthcare arena. This paper attempts to add to the process of better understanding how an open interactive approach can maximize the potential of the concept of connected health. We categories healthcare firms into open innovation profiles, outline examples of open innovation approaches adopted by pharmaceutical firms, and propose an open innovation framework for connected health. Undoubtedly, connected health is a complex concept owing to its heterogeneity and more and more future research needs to focus on exploring how the vital concept can be integrated in the healthcare system to improve and advance outcomes.

\section{CONFLICT OF INTEREST}

The authors wish to confirm that there are no known conflicts of interest associated with this publication.

\section{ACKNOWLEDGEMENTS}

The authors would like to thank Ms. Alica May for her help in revising the figure as per the publication specifications.

\section{REFERENCES}

[1] Chesbrough $\mathrm{H}$. The logic of open innovation: managing intellectual property. Cal Man Rev 2003; 45(3): 33-58.

[2] Chesbrough H, Vanhaverbeke W, West J, Eds. New frontiers in open innovation. UK: Oxford University Press 2014; pp. 1-345

[3] Brunswicker S, Vanhaverbeke W. Open innovation in small and medium sized enterprises (SMEs): External knowledge sourcing strategies and internal organizational facilitators. J Small Bus Man 2015; 53(4), 124163.

[4] Pagliari C. Design and Evaluation in eHealth: Challenges and Implications for an Interdisciplinary Field. J Med Int Res 2007; 9(2): 1-15.

[5] Dooris M. Expert voices for change: Bridging the silos-towards healthy and sustainable settings for the 21 st century. Health Place 2013, 20(2013): 39-50.

[6] Brodie J. Open Innovation in Health Care Management in the UK? Reflecting on the Challenges and Opportunities. J Hosp Med Man 2015; 1(2015): 1-3.

[7] Mullins. Open innovation in Healthcare. Available from: http://www.paconsulting.com/introducing-pas-media-site/highlighting-pasexpertise-in-the-media/opinion-pieces-by-pas-experts/health-servicejournal-open-innovation-in-healthcare-october-2010/ [Cited: 10th December 2015].

[8] Eaton MA. Why healthcare open innovation is failing for nanomedicines. Eur J Nanomed 2013; 5(4): 213-15.

[9] OI Pharma Partners. Why open innovation? Available from: http://www.oipharmapartners.com/ [Cited: 14th December 2015].

[10] Page T. Notions of innovation in healthcare services and products. Int J Innov Sust Dev 2014; 8(3): 217-31.

[11] Thakur R, Hsu SH, Fontenot G. Innovation in healthcare: Issues and future trends. J Bus Res 2012; 65(4): 562-69.

[12] Boote J, Baird W, Beecroft C. Public involvement at the design stage of primary health research: a narrative review of case examples. Health Pol 2010; 95 (1): 10-23.

[13] Dahlander L, Gann DM. How open is innovation? Res Pol 2010; 39(6): 699-09.

[14] Kuenne CW, Moeslein KM, Bessant J. 2013. Towards Patients as Innovators: Open Innovation in Health Care. In: Mukhopadhyay C, Akhilesh KB, Srinivasan R, Gurtoo A, Ramachandran P, Iyer PP, Mathirajan M, Bala Subrahmanya MH, Eds. Driving the Economy through Innovation and Entrepreneurship. India: Springer 2013; pp. 315-27.

[15] Zolfagharifard E. UK engineer develops own life-saving implant: The Engineer; 2011. Available from: http://www.theengineer.co.uk/ukengineer-develops-own-life-saving-implant/ [Cited: 11th December 2015]. 
[16] Boote J, Telford R, Cooper C. Consumer involvement in health research: a review and research agenda. Health Policy 2002; 61(2): 213-36.

[17] Innovahealth. Building an open innovation ecosystem in Europe for healthcare. Available from: http://cordis.europa.eu/result/rcn/58703_en.html [Cited: 25th January 2015].

[18] Verbano C, Crema M, Venturini K. The Identification and Characterization of Open Innovation Profiles in Italian Small and Medium-sized Enterprises. J Small Bus Man 2015; 53(4):1052-75.

[19] Segers JP. Strategic Partnerships and Open Innovation in the Biotechnology Industry in Belgium. Technol Innov Man Rev 2013; 3(4): 23-28.

[20] Lilly OIDD. Open Innovation Drug Discovery Programme. Available from: https://openinnovation.lilly.com/dd/includes/pdf/OIDD_Brochure.pdf [Cited: 27th January 2016]

[21] Chorus Pharma. Global innovation for value creation. Available from: https://choruspharma.com/about-us.html [Cited: 27th January 2016]

[22] GSK Open Centre of Excellence. Available from: http://www.outsourcing-pharma.com/Preclinical-Research/GSKopensCentre-of-Excellence [Cited: 25th January 2016]

[23] Centers for Therapeutic Innovation. Available from: http://www.pfizer.com/research/rd_partnering/centers_for_therapeutic_inno vation [Cited: 12th February 2016]

[24] Schuhmacher A, Germann PG, Trill H, et al. Models for open innovation in the pharmaceutical industry. Drug Disc Tod, 2013; 18(23):1133-37.

[25] Caulfield, BM, Donnelly SC. What is Connected Health and why will it change your practice? QJM: An Int J Med 2013; 106(8): 703-07.
[26] Tolhurst L, Brown J. Challenges faced by multinational food and beverage corporations when forming strategic external networks for open innovation. In: Martinez MG, Ed. Open Innovation in the Food and Beverage Industry. UK: Woodhead Publishing Limited 2013; pp. 294-11.

[27] Radnejad AB, Vredenburg H. Collaborative competitors in a fastchanging technology environment: open innovation in environmental technology development in the oil and gas industry. Int J Entrepren Innov Man 2015; 19(1-2):77-98.

[28] Bigliardi B, Ivo Dormio A, Galati F. The adoption of open innovation within the telecommunication industry. Eur J Innov Man 2012; 15(1): 27-54.

[29] Deloitte Center for Health Solutions. Executing an open innovation model: Cooperation is key to competition for biopharmaceutical companies, 2015. Available from: https://www2.deloitte.com/us/en/pages/life-sciencesand-health-care/articles/biopharma-open-innovation.html\# [Cited: 10th November 2016].

[30] Deloitte Center for Health Solutions Report. Connected health: How digital technology is transforming health and social care, 2015. Available from: $\quad$ https://www2.deloitte.com/uk/en/pages/life-sciences-andhealthcare/articles/connected-health.html [Cited: 8th November 2016].

[31] iNNOVAHEALTH Cyprus EU Presidency. Building an Open Innovation ecosystem in Europe for healthcare iNNOVAHEALTH Conference, Larnaca, Cyprus, October 2012. Available from: http://img.euapm.eu/resources/eapmmanifesto.pdf [Cited: 14th November 2016].

[32] Galbraith B, Mulvenna M, McAdam R, et al. Eds. Open innovation in connected health: an empirical study and research agenda. Proceedings in a conference on open innovation: creating products and services through collaboration (ISPIM-2008); 2008 June 15-18; Tours (Loire Valley), France.

[33] Randhawa K, Agarwal R, Josserand EL. Eds. Strategically aligning a culture of 'open innovation'in organizations. Proceedings in 27th ANZAM Conference: Managing on the Edge Proceeding; 2013 January; Australia. 